
\title{
$\begin{array}{ll}\text { Research Square } & \begin{array}{l}\text { Preprints are preliminary reports that have not undergone peer review. } \\ \text { They should not be considered conclusive, used to inform clinical practice, } \\ \text { or referenced by the media as validated information. }\end{array}\end{array}$
}

\section{The Physicians' Oath through the Eyes of the Bulgarian Medical Students: Empirical Survey}

Juliana Krumova Marinova ( $\nabla$ julie.marinova@gmail.com )

Trakijski Universitet Stara Zagora https://orcid.org/0000-0001-8178-4369

\section{Boryana Mitkova Parashkevova-Simeonova}

Trakia University, Stara Zagira

\section{Galya Dimitrova Chamova}

Trakia Universty, Stara Zagora

\section{Galina Ilieva Petrova}

Trakia University, Stara Zagora

\section{Vanya Bancheva Slavova}

Trakia University, Stara Zagora

Krasimira Tosheva Benkova

Trakijski Universitet Stara Zagora

\section{Research article}

Keywords: Hippocratic Oath, Declaration of Geneva, Medical ethics, Medical students, Self-administered questionnaire, Perceptions, Preferences

Posted Date: August 9th, 2019

DOl: https://doi.org/10.21203/rs.2.12523/v1

License: (c) (i) This work is licensed under a Creative Commons Attribution 4.0 International License.

Read Full License 


\section{Abstract}

Background Upon graduation physicians in Bulgaria are required by law to take the Hippocratic Oath and its' different adapted variants are used in the medical schools. The goal of this survey was to investigate medical students' in 4th, 5th and 6th year of their undergraduate training perception and preferences about the two versions: the adapted Hippocratic Oath currently used in one medical school (Version-1) and the newly-revised Declaration of Geneva "The Physician's Pledge", 2017 (Version-2). Methods An empirical survey was carried out, using direct individual self-administered questionnaire from February to April 2018. Students' lists of total 239 medical students provided by the institution's authority were used. 183 students responded (total response rate of $76.57 \%$ ). Methods of descriptive and analytical statistics were used based on the nature of the data: relative frequency distributions, Pearson Chi-Square nonparametric test for hypothesis assessment - statistical significance was set at $p<0.05$. Results In a closed response binominal question force choice format respondents gave higher preference as overall perception to Version-1 (61.7\%) and there were not statistically significant differences according to their basic socio-demographic characteristics (Pearson Chi-Square test $-p>0.05$ for all hypotheses). The ranking of the clauses of the preferred version considered to be decisive indicated the highest preference to the wording in the two versions referring to the field of professional relationships in doctor-patient sphere: the doctor's obligation to always be ready to provide medical care from the Version-1 (54.5\%) and the nondiscrimination about the Version-2 (41.4\%). In the particular aspect of the relations between teachers, students and colleges and the respect for human life, preferences were rather pointing to the wordings of the Version-2: respectively $54.4 \%$ and $63.2 \%$ of respondents and in the area of doctor-patient relationships greater preference was given to the wording of the Version-1: $59.3 \%$ of respondents. Conclusions The current survey was inspired by the latest revision of the Declaration of Geneva. There are the position expressed by the students towards both Oath versions as a bond between tradition and reality. Our finding could serve for further discussions regarding the Bulgarian practice of administering the Physicians' Oath.

\section{Background}

Upon graduation, receiving a "Physician" professional qualification, at an official ceremony in a solemn atmosphere, young doctors in the Republic of Bulgaria are required to take the Hippocratic Oath. This ritual is a tradition in our country and is seen as the most famous professional rite of passage [1]. Also, this requirement is enshrined in the Bulgarian health legislation. At present Article 176 (1) of the Bulgarian Health Act (2005) reads as follows: "Upon receiving their diplomas, all medical doctors and dentists shall take the Hippocratic oath." [2].

Historically, the Hippocratic Oath has been obligatory for all doctors upon graduation since the establishment of the Medical Faculty at the University of Sofia in 1918 - that is, from the very beginning of the training of doctors in Bulgaria after the Liberation. Before the Second World War an Oath, "slightly different" than the Hippocratic Oath had been applied. At the time of socialism the Hippocratic Oath was abolished in 1952, later in 1973 was adopted the Russian Oath. The Hippocratic Oath was reintroduced in 
1994 during the period of considerable political and socio-economic changes after the landmark year of 1989 and the restoration of the Bulgarian Physicians' Association the existence and activities of which were prohibited for 43 years: 1947-1990 [3-7].

An adapted version of the Hippocratic Oath currently applied in one of the medical schools in Bulgaria has been accepted by the Faculty Council since 2012 (Additional file 1). This is only one of the modified texts of the Hippocratic Oath, representative for the modern Bulgarian medicine [1]. This adaptation strives to address the challenges in the context of professional ethics of physicians in modern society. This version cleans up elements considered inadequate for the current national health system. The most striking examples in this field are problems related to the beginning and the end of life, particularly the liberal regulation of abortion and the complete ban on euthanasia in the Republic of Bulgaria. The adapted version is also called "Hippocratic Oath" preserving the spirit of the oath as a sign of the continuity and eternity of values traditionally associated with the humanity and dedication of the medical profession.

The Declaration of Geneva, adopted by the World Medical Association (WMA) at its Second General Assembly in 1948, presents in a concise form the basic professional duties of the physician and reaffirms the vital ethical principles of the medical profession $[8,9]$. The Hippocratic Oath was the basis of the WMA's Declaration of Geneva - the first document of global bioethics [10]. For 70 years since its adoption, the Declaration has undergone six revisions and amendments approved by the General Assembly of the WMA in 1968, 1983, 1994, 2005, 2006 and 2017, respectively. The chair of the WMA's Declaration of Geneva workgroup highlighted the changes in the newly revised document, reflecting challenges and needs of the modern medical profession such as the doctor-patient relationship, confidentiality, respect for teachers and colleagues. New additions to the Declaration are: "I will respect the autonomy and dignity of my patient" included as $3^{\text {rd }}$ clause; "I will share my medical knowledge for the benefit of the patient and the advancement of healthcare" clause 11; "I will attend to my own health, well-being, and abilities in order to provide care of the highest standard" clause 12. The respect for teachers, colleagues and students is expressed in one sentence: "I will give to my teachers, colleagues, and students the respect and gratitude that is their due", making the previously used "My colleagues will be my sisters and brothers" redundant. It is noteworthy that the term "well-being" is added next to "health", amending a clause to state that the "health and well-being of my patient will be my first consideration". The amendment to the existing clause that calls for a physician to practice with conscience and dignity by adding "in accordance with good medical practice" also deserves attention. It is worth highlighting that the declaration is titled "The Physician's Pledge" [8, 9].

The substantial changes and additions to the newly revised Declaration of Geneva - "The Physician's Pledge", directs the authors' of this manuscript interest in investigating the perception and preferences of medical students during the second half of their undergraduate education to both versions of the Oath: the one accepted by the medical school, and the newly-revised Declaration of Geneva. Which of the two versions do they prefer and why? 
The goal of this survey was to investigate the perception and preferences of the students of medicine in $4^{\text {th }}, 5^{\text {th }}$ and $6^{\text {th }}$ year of their study at the Medical School, about the two versions of the Oath: the one used by the Medical School, and the newly-revised Declaration of Geneva. To achieve this goal, we have set the following tasks: to identify students' preference for one of the two presented versions of the Physicians' Oath as overall perception; to present the main elements of the preferred version that the students consider to be decisive; to outline students' position towards the way the new mutual respect between teachers, colleagues, and students; the respect for human life and the relationships with patients is presented in both versions of the oath; to present the arguments in favor of the preferred version, expressed by the students using their words and means of expression.

\section{Methods}

\section{Survey design}

In order to achieve the stated goal and objectives, an empirical sociological study was carried out, using direct individual self-administered questionnaire, adhering to the basic principles of voluntariness and anonymity. The questionnaire was developed by the authors, taking into account the features of the sociological method applied as well as the specifics of the research problem. Both versions of the Oath are attached to the questionnaire and the query is presented as follows: "We present to your attention two versions of the Oath: The first version is the "Hippocratic Oath" currently applied in the Medical School: Version-1. The second version is the World Medical Association Declaration of Geneva "The Physician's Pledge", last revision 2017: Version-2 - (the translation from original English is subject of discussion in order to achieve optimal translation in Bulgarian)." Students were asked to reply the questions listed after having read carefully the text of both versions: "We would appreciate you taking the time to complete the questionnaire, after you read the text of both Oaths carefully." The translation of the Declaration of Geneva "The Physician's Pledge" from original English was made by the authors, taking into account terms and formulations used in the previous editions of the document, published in Bulgarian [11, 12]. All the 12 questions were structured along with answers that best serve the goals and objectives of the research. This instrument was pilot tested by eight physicians, faculty members. The survey was approved for conduction by the Medical School Ethics Committee.

\section{Variables}

The preference for one of the two versions as overall perception was expressed in one closed response binominal question force choice format.

The elements of the preferred version, considered to be decisive, were marked by selecting the respective number of up to 3 clauses from the chosen version.

Students' position towards the way the new mutual respect between teachers, colleagues, and students; the respect for human life and the relationships with patients is presented in both versions of the oath 
was outlined in three questions through an alternative choice of formulations, respectively, laid out in the two versions of the oath.

Arguments to support the preferred version of the students were presented using their words and means of expression in an open-ended question, asking them to write "at least one argument".

Basic socio-demographic characteristics of the participants included sex, age, citizenship, year of study and religion in 5 relevant questions.

\section{Setting and participants}

All the medical students having passed half of their undergraduate university education were defined as the subject of the study $(n=239)$ : at their $4^{\text {th }}, 5^{\text {th }}$ and $6^{\text {th }}$ year of study at the Medical School. The survey period is from February to April 2018. The students' lists of total 239 medical students provided by the Medical School Academic Affairs Division were used and there were no exclusion criteria for participation in the study. A single point of contact was assigned for each of the 30 students groups. All of them were instructed prior to the research about their role and responsibilities concerning the inquiry. We chose this approach in order to have more certainty that the questionnaire will reach every student and will be correctly completed and returned. 183 students responded, filled in appropriately and returned the questionnaire out of 239 people in total, i.e. a total response rate of $76.57 \%$.

\section{Statistical Processing and Data Analysis}

A database was built using SPSS v.21. Methods of descriptive and analytical statistics were used based on the nature of the data: relative frequency distributions, Pearson Chi-Square nonparametric test for hypothesis assessment - statistical significance was set at $p<0.05$.

\section{Results}

Socio-demographic characteristics of the group of students surveyed: The distribution of the students by sex, age, citizenship, year of study and religion is presented in Table 1.

Distribution by sex: Two thirds of the respondents are women - 122 (66.7\%), which is in correspondence to the process of feminization of the medical profession. The average age of the respondents is 23.82 years $(S D=1.9)$, the extreme one is 42 years for one student. The majority of the students are citizens of the Republic of Bulgaria - 167 (91.3\%). Respondents' religion: A significant proportion of students have Christian religion - 133 (72.7\%), Muslims are 44 students (24.0\%) and 6 students pointed out another religion. Thus, a group of respondents is formed, relatively homogeneous by age; predominantly female; Bulgarian citizens; with Christian religion affiliation.

Distribution by year of study: The students in their $5^{\text {th }}$ grade comprise the largest share: 75 (41\%), followed by the $4^{\text {th }}$ grade: $67(36.6 \%)$, and in $6^{\text {th }}$ grade, with share of $41(22.4 \%)$. Students in $5^{\text {th }}$ and $6^{\text {th }}$ grade together represent almost two thirds of the respondents - $63.4 \%$. It is important to note that they 
have either completed their 10-semesters education ( $6^{\text {th }}$ grade trainee-doctors) or are in their final semester. Students in $4^{\text {th }}$ grade continue their university theoretical and practical education. During the discussions of the selection criteria for the students to be included in the survey, we considered the importance of the learning phase in which they currently are. Students in the second half of their education would have their own experience, skills, impressions, formed in practical training and helping them to get closer to the professional thinking and professional moral of the medical profession. All students participating in the survey have completed a mandatory course in Medical Ethics during their first year, early stage of undergraduate education without having at that point direct contact with real clinical practice. (Medical Ethics mandatory training as a separate course for medical students was introduced in the early 1990s in medical schools in Bulgaria. In the general part of the syllabus the ethical codes are accentuated with a thorough presentation and analysis during lecture course and practical sessions.)

Students' preference as overall perception for one of the two versions of the Oath presented:

At a closed response binominal question force choice format: "Which of the two versions of the Oath you prefer more?" the students respond as follows: almost two-thirds - $113(61.7 \%)$ of the students prefer Version-1 the Hippocratic Oath; the remaining 70 students (38.3\%) - Version-2 the Declaration of Geneva of the proposed versions. Format of the question, the subjective assessments and attitude of both students and researchers are of great importance for interpretation of this result. It is obvious and undisputed that the majority of students give preference to Version-1 - the adapted version of the Hippocratic Oath. However, this does not provide a clear trend therein as almost $40 \%$ of the respondents prefer Version-2 - the newly-revised Declaration of Geneva. We do not find statistically significant differences in students' answers according to the basic socio-demographic characteristics described above - evaluated using the Pearson Chi-Square test - $p>0.05$ for all hypotheses presented in Table 2 . This preference is much more likely to be influenced by the value orientations and beliefs of young people, who have gained some experience during their medical training.

The main elements of the preferred version that students consider to be decisive are presented based on a request to students to select and mark the three most important clauses from the version preferred by them. Ranking of the selected clauses is presented in Table 3 and Table 4.

Students choosing Version-1: Ranking of the selected and tagged clauses indicates the highest preference for: "To always be ready to help those in medical need", in the answers of 60 students (54.5\%), in the first position followed by "To dedicate all my abilities and knowledge to protect and improve the health of humans" - indicated by 54 students $(49.1 \%)$ and the next "To recommend a healthy lifestyle to my patients, to protect them from things dangerous and harmful, to treat them with care and to keep the confidentiality" - according to 50 students (45.5\%). 
Students choosing Version-2: Ranking of the selected and tagged clauses show preference in the highest extent for the: „I will not permit considerations of age, disease or disability, creed, ethnic origin, gender, nationality, political affiliation, race, sexual orientation, social standing, or any other factor to intervene between my duty and my patient", reported in the answers of 29 students (41.4\%), in the first position followed by "The health and the well-being of my patient will be my first consideration", in the second position - indicated by 28 students (40.0\%) and the next "I will maintain the utmost respect for human life", indicated by 24 students (34.3\%).

Through this ranking we strive to focus on the most significant texts and wording of the preferred version of the Oath presented through the prism of future physicians. The non-discrimination of the patient is mainly indicated by the students who preferred Version 2, and the important feature of the professional ethics of the doctor to always provide medical care is mainly indicated by the students who preferred Version-1.

The next task we pursue in our study is to outline students' positions towards the way the relations between teachers, students and colleagues, the respect for human life, and the relationships with patients in both versions of the Oath are presented. To achieve this, we asked questions with an alternative choice of wordings from both versions.

Aspects of relations between teachers and colleagues: alternative choice between: "I pledge to my teachers the respect and gratitude that is their due"; in Version-1 and "I will give to my teachers, colleagues, and students the respect and gratitude that is their due"; in Version-2. 99 (54.4\%) out of the 182 students who answered the question, opted for the text of Version-2. The other 83 students (45.6\%) point they prefer the wording in Version-1. Concerning this area of relationship, the respondents' preference is toward the wording of the newly-revised Declaration of Geneva presented by more than half of them.

The respect for human life: alternative choice between: "To refuse of any call for use of lethal venom"; in Version-1 and "I will maintain the utmost respect for human life"; in Version-2. 115 (63.2\%) out of the 182 students who answered the question, opted for the text of Version-2 and the remaining 67 students $(36.8 \%)$ point they prefer the wording in Version 1 . The result shows that in this particularly sensitive and controversial area, such as professional duty and responsibility, the wording of the newly-revised Declaration of Geneva is preferable.

Relationships with patients: alternative choice between: "To recommend a healthy lifestyle to my patients, to protect them from things dangerous and harmful, to treat them with care and to keep the confidentiality" in Version-1 and "I will respect the autonomy and dignity of my patient." and "I will respect the secrets that are confided in me, even after the patient has died."; in Version-2. The larger part of the students select as preferred the wording in Version-1 - 108 (59.3\%) out of the 182. The remaining 74 students $(40.7 \%)$ state they like more Version 2 formulation. In this area a greater preference is given to the wording of the adapted Hippocratic Oath - Version-1. 
Despite the above presented overall preference of students towards Version-1 - the modified Hippocratic Oath in the particular aspect of the relations between teachers, students and colleagues and the respect for human life the preferences are rather pointing to Version-2, i.e. the newly revised Declaration of Geneva. We could assume that these preferences are associated with the above presented overall preference for a particular version of the Oath. This is especially impressive with regard to students who preferred Version- 2 and chose the corresponding wording from the same Version: $81.2 \%$ for the respect for teachers and colleagues; $94.2 \%$ for the respect for human life; $72.5 \%$ for doctor - patient relationships. The assessment of the hypotheses confirms the existence of a statistically significant difference between the preference for the corresponding version and the choice of formulations presented in the three areas for all three hypotheses assessed using the Pearson Chi-Square test - $p<0.001$ (not shown here).

The survey contains an open-ended question asking students to write in their own words at least one argument in favor of their preferred version. Students selecting Version-1 as preferred: It is noteworthy that most of the arguments presented often contain expressions and words that we could summarize in the following directions: 1 . The most commonly used comments are those related to the tradition, the historical roots of the profession, the continuity of the generations of physicians with words and phrases such as: "tradition", "Hippocratic", "established in time", "classical", "history", "the historical roots of medicine", "because of the tradition and the fact that, despite the pagan gods, the words spoken in it are principles that have been and will always be relevant to the art of the medical profession"; "the symbol of the medical profession since ancient times has been the Hippocratic Oath ....it is a tradition that must continue"; "... a pillar between the past, the present and the future..."; "respect for history"; 2 . Next are those related to the impact and sound of the oath: "more prominent and stronger", "more solemn", "more emotional", "sounds more poetic", "would make me feel part of something very important ...", "the text is more beautiful"; 3. "Clear", "understandable", "accurate" also appear in some of the comments. Students selecting Version-2 as preferred: The arguments are mainly related to the topicality of the oath, its modern sounding and its impact: 1 . The most commonly used are: "modern", "up-to-date", "closer to present-day times", "supports more accurately the progressive ideals of today's medicine", "meets today's norms in society", "realistic", "adequate to current trends", "... contemporary version, in which phrases are closer to the nowadays' physician", "more prevailing", "More up-to-date and embracing aspects and values that in the past were not in the foreground and do not appear in the oath"; 2 . some arguments emphasize certain aspects of the moral image, obligations and rights in the practice of the profession, especially in the field of doctor-patient relationship: "... I think it reflects much better the duties doctor owes to the patient and the profession integrity", "Takes into account the patient's autonomy and awareness", "...meets modern requirements for understanding the patient and our responsibilities", "... reflects in a realistic way the moral values that a physician must possess and duties to perform ..." ; 2 . The sound and impact of the oath are also expressed: "sounds progressive", "sounds more contemporary", "more understandable and comprehensive", "more detailed", "more balanced and better sounding", "Sounds more modern".

\section{Discussion}


The goal of this survey was to investigate the perception and preferences of the students of medicine in $4^{\text {th }}, 5^{\text {th }}$ and $6^{\text {th }}$ year of their study about the two versions of the Oath: the one adopted by the Medical School, and the newly-revised Declaration of Geneva. To achieve this goal , we identified students' preference for one of the two presented versions of the Physicians' Oath as overall perception; we presented the main elements of the preferred version that the students consider to be decisive; we outlined students' position towards the way the new mutual respect between teachers, colleagues, and students; the respect for human life and the relationships with patients is presented in both versions of the oath; and also we presented the arguments in favor of the preferred version, expressed by the students using their words and means of expression.

The prevailing preferences pointing to the adapted Hippocratic Oath as overall perception, without a clear trend in this direction, as more than a third of respondents prefer Version-2 - the newly-revised Declaration of Geneva, in our opinion, is referable to the current Bulgarian medical professional, social and political situation. The Hippocratic Oath is well-known and widely popular in Bulgaria. In the Hippocratic Oath are highlighted all important moral aspects of a doctor's behavior both in professional settings and generally in society [13]. It is a legal requirement for every newly graduated medical doctor to take the Hippocratic Oath. Different modified variants of the Hippocratic Oath have been applied by different autonomous medical schools in the country. The Physician's Oath, no matter the wording of the text, is administered under the name "Hippocratic Oath". Bulgarian scientists have focused research and publications in this field predominantly on the Hippocratic Oath, both classic and modified $[1,3,4,14]$. The effort for modernizing the Hippocratic Oath is actually pushing it more away from the original and the name "Hippocratic Oath" abides as a symbol of the medical profession as it has been for all the millennia since Hippocrates. We would not be able to compare results of our study to others conducted in Bulgaria because by now there are not similar ones directed to the Declaration of Geneva. At the same time it could be assumed that the Declaration of Geneva is yet not popular enough in Bulgaria as well as worldwide: "...the Declaration of Geneva is only rarely used as an oath text despite the fact that physicians' oaths are generally widespread [15]. However, more than a third of medical students give preference as overall perception to the newly-revised Declaration of Geneva, a fact that should not be underestimated.

Through the ranking of the selected clauses considered to be decisive we strive to focus on the most significant texts and wording of the preferred version of the Oath presented through the prism of future physicians. It is worth paying attention at the fact that the non-discrimination of the patient is mainly indicated by the students who preferred Version 2, and the important feature of the professional ethics of the doctor to always provide medical care is mainly indicated by the students who preferred Version- 1 . Based on the above ranking we could summarize that the clauses related to the professional relationships and ethical behavior in the doctor-patient sphere are being considered of the highest importance concerning both versions. Perhaps doctor-patient relationship is the guiding, the most important area for the future physicians undergoing medical training which made them express such preference in both cases. This result reflects the understanding about the essence of the medical 
profession, associated primarily with doctor-patient relationships from antiquity to the present days: "Medicine begins with the doctor - patient relationship...", [16], "...the Oath has established the general context of medical ethics of physician-patient relationship, which reflects long-lasting moral values that still define the medical profession" [17].

According to the study results presented above a greater preference is expressed for the wordings in the newly revised Declaration of Geneva, towards the respect for human life and the relationships between teachers, colleagues and students. Clearly, important aspects of the pointed areas are reflected in the students' preferences for the wording in Version-2 as it could be considered more relevant for the challenges of the present days. This result is understandable and logical given the problems facing the modern medical practice. The relationship between teachers, colleagues and students manifests trends in modern days, with extention of the addressee of respect for the professional community: students, colleagues and teachers. "The respect for human life" encompasses a widening range of multifactorial problems, in which almost two thirds of our respondents show preference for Version-2. This in the context of changing social expectations towards the medical practice, shaped by accelerated development in technology, combined with scarce resources. The text in Version-1: "To refuse of any call for use of lethal venom" relates directly to the ban of euthanasia stated in Article 97 of the Bulgarian Health Act (2005): „No euthanasia shall be applied within the territory of Bulgaria.” [2]. This, however, does not preclude further discussions on the matter, especially with the lack of clear definition of "euthanasia" written in the law. Such discussions have been taking place in the scientific community and the Bulgarian Parliament, following changing perceptions and values in society $[18,19]$. A multifaceted array of problems concerning "The utmost respect for human life" does not entail only the euthanasia as mentioned above, they include a much wider range of dilemmas in the modern medical practice open for discussions. Among them the delineation of notions as "acceptable" and "permissible" with regard to human life and human dignity is getting blurrier nowadays.

The process of healthcare reform in the Republic of Bulgaria is connected with serious ethical challenges and these in the sphere of doctor - patient relationships are crucial. Respondents' greater preference to the wording of the adapted Hippocratic Oath concerning the area of doctor - patient relationships could be discussed in the context of complicated ethical issues associated with exercising and respecting the rights, obligations and responsibilities of the physician and the patient in terms of medical practice incorporating the concepts of patient autonomy, patients' rights and informed consent. Legislative foundation (Bulgarian Health Act, 2005 [2] has been amending and supplementing continuously since its adoption) and ethical regulation (Code of Professional Ethics of the Physicians in Bulgaria, 2000, 2013) [20]) of this practice in Bulgaria is in accordance with basic official documents of the European Union and fundamental ethical codes: International Code of Medical Ethics; World Medical Association Declaration of Geneva; The Hippocratic Oath [7, 21-23].

Based on the above presented arguments from the open-ended question we could summarize the expressed students' position towards both Oath Versions as bond between tradition and reality a linkage 
between the symbolic start in the profession with the act of taking the Hippocratic Oath and the acceptance of the responsibilities of modern physician in today's global world.

\section{Limitations}

We are aware of the limitations in the current survey owed to the methodology of the empirical sociological research; the design of the questionnaire; the response rate of the students, which in this study amounts to $76.57 \%$; and also our personal views and convictions which could have influenced the presentation and discussion of the study results.

\section{Conclusions}

Medical students prefer Version-1- the adapted version of the Hippocratic Oath, without a clear trend in this direction, as more than a third of them prefer Version-2 - the newly-revised Declaration of Geneva. The students set the greatest importance to the wording in the two texts referring to the field of professional relationships and ethical behavior in doctor-patient sphere. Despite the prevailing overall preference towards the modified Hippocratic Oath in the particular aspect of the relations between teachers, students and colleges and the respect for human life, preferences are rather pointing to the newly revised Declaration of Geneva. We could summarize the position expressed by the students towards both Oath versions as a bond between tradition and reality. A link between the symbolic start in the profession with the act of taking the Hippocratic Oath as a sign of continuity and eternity of values traditionally relate to the humanity and dedication of the medical profession, and its deep historical roots from the classical age in Ancient Greece, and the acceptance of the responsibilities of the modern physician in today's global world. The challenges of current time for the professional accomplishment of the modern physician are multidimensional. The modern physician is part of modern society, all medical values are inevitably influenced by the society and this influences the moral image of the doctor. The challenges modern medicine faces are clearly demonstrated through the adaptation and revision of important documents, and the Oath is undoubtedly the most substantial of them. The current survey has been inspired by the latest revision of the Declaration of Geneva. Our finding could serve for further discussions regarding the Bulgarian practice of administering the Physicians' Oath.

\section{Abbreviations}

WMA: the World Medical Association

\section{Declarations}

\section{Ethics approval and consent to participate}

The survey was approved by the Ethics Committee of the Medical Faculty of Trakia University - Stara Zagora (Meeting Minutes No. 6 of the Ethics Committee session). All respondents signed a consent form 
before completing the questionnaire and responses were anonymous.

\section{Consent for publication}

Not Applicable.

\section{Availability of data and material}

Data available by contacting the corresponding author.

\section{Competing interests}

The authors declare there are no competing interests.

\section{Funding}

The research was funded by the Medical Faculty, Trakia University - Stara Zagora: Scientific Project № $11 / 2017$.

\section{Authors' contributions}

JM and BP contributed in study conception and design; GP, GCh, VSI, and KB collected the data; GCh, BP, $\mathrm{JM}$ analyzed the data; JM, BP, GCh developed the manuscript; all authors read and approved the final manuscript for submission.

\section{Acknowledgments}

We thank the medical students for their participation in the study. We also thank Chubrina Racheva, Svetlana Parashkevova, Velcho Nanchev and Janka Ivanova for their consultations during the process of article translation.

\section{References}

1. Popivanov PI. Hippocratic Oath in Modern Bulgaria. General Medicine. 2012; 14 (4): 48-52 (in Bulgarian).

2. Health Act. Promulgated, SG No. 70/10.08.2004, effective 1.01.2005, supplemented, SG No. 46/3.06.2005, last amended and supplemented No.102/11.12. 2018 (in Bulgarian).

3. Apostolov M., Vasilev VI. New Translation and New Interpretation of the Hippocratic Oath. Hygiene and Healthcare. 1992.; 35 (5): 42-45. (in Bulgarian).

4. Apostolov M. Historical, Social and Ethical Dimensions of Medicine. 5th Edition. Sofia: GorexPres; 2006. (in Bulgarian).

5. Vodenitcharov Tz., Popova S. Medical Ethics. 2nd edition. Sofia: Open Society Foundation; 2006. (in Bulgarian). 
6. Dimitrov B., Glutnikova Z., Dimitrova B. Education and Practice of Medical Ethics in Bulgaria after Political and Socio-Economic Changes in the 90's. Ethics \& Medicine. 2007; 23(1): 11-14.

7. Alexandrova-Yankulovska S. Bulgaria. In: Henk A. M. J. ten Have and Bert Gordijn, editors. Handbook of Global Bioethics. Springer Dordrecht Heidelberg New York London: Springer Science+Business Media Dordrecht; 2014. p. 905-924.

8. The World Medical Association Declaration of Geneva, Adopted by the 2nd General Assembly of the World Medical Association, Geneva, Switzerland, September 1948 and amended by the 22nd World Medical Assembly, Sydney, Australia, August 1968 and the 35th World Medical Assembly, Venice, Italy, October 1983 and the 46th WMA General Assembly, Stockholm, Sweden, September 1994 and editorially revised by the 170th WMA Council Session, Divonne-les-Bains, France, May 2005 and the 173rd WMA Council Session, Divonne-les-Bains, France, May 2006 and amended by the 68th WMA General Assembly, Chicago, United States, October 2017. https://www.wma.net/policies-post/wmadeclaration-of-geneva/.

9. Parsa-Parsi RW. The Revised Declaration of Geneva a Modern-Day Physician's Pledge. JAMA. 2017; /doi.org/10.1001/jama.2017.16230.

10. Baker R. Codes of Conduct. In: Henk A. M. J. ten Have. and Bert Gordijn, editors. Handbook of Global Bioethics. Springer Dordrecht Heidelberg New York London: Springer Science+Business Media Dordrecht; 2014. p.551-580.

11. Boyadjiev B., Tomova S., Onchev G. Doctor, Patient, Society. Human Rights and Professional Responsibility of the Doctor in Instruments of International Organizations. Compilation and Translation by B. Boyadjiev, S. Tomova, G. Onchev, overall editing by B. Boyadjiev. Sofia: Foundation Neurosciences and Behavior; 1994 (in Bulgarian).

12. Alexandrova-Yankulovska S. Bioethics. 1st edition. Pleven: Publishing Center of Medical University of Pleven; 2010. (in Bulgarian).

13. Borisov V. Doctor between standards and vocation. Medical Meridians. 2012 (3): 3-9. (in Bulgarian).

14. Markova S., Marinova J., Dimitrova S., Dimitrov B. Opinions and Attitude of Medical students towards basic principles of the Hippocratic Oath. Ethics \& Medicine, 1999;15: 66-69.

15. Rheinsberg Z., Parsa-Parsi R., Kloiber O. et al. Medical oath: use and relevance of the Declaration of Geneva. A survey of member organizations of the World Medical Association (WMA). Med Health Care and Philos. 2018; org/10.1007/s11019-017-9794-x.

16. Callahan D. The goals of medicine. Setting new priorities. International Project of the Hastings Center, USA. translation from English S. Popova, E. Nencheva. Sofia:TEMPO Publishing House; 1998. (in Bulgarian).

17. Askitopoulou H., Vgontzas AN. The relevance of the Hippocratic Oath to the ethical and moral values of contemporary medicine. Part II: interpretation of the Hippocratic Oath-today's perspective. Eur Spine J . 2018; org/10.1007/s00586-018-5615-z

18. Mancheva P., Kerekovska A., Radionova D., Madjova V., Euthanasia in Bulgaria - legal and medical aspects. Social Medicine. 2012; (4):13-15 
19. Mancheva P. Euthanasia - the other outcome. Varna: STENO Publishing House; 2013 (in Bulgarian).

20. Code of Professional Ethics of the Physicians in Bulgaria. SG 79/29.09.2000, amended and supplemented, SG No. 85/28.09.2013.

21. Zinovieva D., Salchev P. Rights of patient. Sofia: Publishing House "Siela”; 1998 (in Bulgarian).

22. Dimitrova S. Informed consent in medical practice. Stara Zagora: Alfamarket Publishing House; 2003 (in Bulgarian).

23. Alexandrova S. Comparative analysis of the Code of Professional Ethics in Bulgaria and the Hippocratic Oath, Declaration of Geneva and International Code of Medical Ethics. Med Law. 2005; 24(3): 495-3.

\section{Tables}

Table 1 Socio-demographic characteristics of the respondents $(\mathrm{n}=183$ )

\begin{tabular}{lrc}
\hline Socio-demographic characteristics & $\mathrm{N}$ & $\%$ \\
\hline Sex & 61 & 33.3 \\
Male & 122 & 66.7 \\
$\quad$ Female & & \\
Age & 83 & 45.4 \\
$\quad$ Under 24 years of age & 100 & 54.6 \\
$\quad$ Aged 24 and over & & \\
Citizenship & 167 & 91.3 \\
$\quad$ Bulgarian & 16 & 8.7 \\
Foreign & & \\
Year of study & 67 & 36.6 \\
4th grade & 75 & 41.0 \\
5th grade & 41 & 22.4 \\
6th grade & & \\
Religion & 133 & 72.7 \\
Christianity & 44 & 24.0 \\
Islam & 6 & 3.3 \\
Another & & \\
\hline
\end{tabular}


Table 2 Students' preference for one of the two Oath's versions by their basic socio-demographic characteristics

\begin{tabular}{|c|c|c|c|}
\hline \multirow[t]{2}{*}{ Socio-demographic characteristics } & $\begin{array}{l}\text { Students preferred } \\
\text { Version } 1 \\
\end{array}$ & Students preferred Version 2 & \multirow[t]{2}{*}{$\mathrm{P}$} \\
\hline & $\mathrm{n}(\%)$ & $\mathrm{n}(\%)$ & \\
\hline \multicolumn{4}{|l|}{ Sex } \\
\hline Male & $35(31.0)$ & $26(37.1)$ & \multirow[t]{2}{*}{$\mathrm{p}>0.05$} \\
\hline Female & $78(69.0)$ & $44(62.9)$ & \\
\hline \multicolumn{4}{|l|}{ Age } \\
\hline Under 24 years of age & $56(49,6)$ & $27(38,6)$ & \multirow[t]{2}{*}{$\mathrm{p}>0.05$} \\
\hline Aged 24 and over & $57(50.4)$ & $43(61.4)$ & \\
\hline \multicolumn{4}{|l|}{ Citizenship } \\
\hline Bulgarian & $102(90.3)$ & $65(92.9)$ & \multirow[t]{2}{*}{$\mathrm{p}>0.05$} \\
\hline Foreign & $11(9.7)$ & $5(7.1)$ & \\
\hline \multicolumn{4}{|l|}{ Year of study } \\
\hline 4th grade & $44(38.9)$ & $23(32.9)$ & \multirow[t]{3}{*}{$\mathrm{p}>0.05$} \\
\hline 5 th grade & $43(38.1)$ & $32(45.7)$ & \\
\hline 6 th grade & $26(23.0)$ & $15(21.4)$ & \\
\hline \multicolumn{4}{|l|}{ Religion } \\
\hline Christianity & $83(73.5)$ & $50(71.4)$ & \multirow[t]{3}{*}{$\mathrm{p}>0.05$} \\
\hline Islam & $28(24.8)$ & $16(22.9)$ & \\
\hline Another & $2(1.8)$ & $4(5.7)$ & \\
\hline
\end{tabular}


To recommend a healthy lifestyle to my patients, to protect them from things dangerous and harmful, $\quad 50$ to treat them with care and to keep the confidentiality;

To constantly improve my knowledge and advance my medical skills, to help with my work the

I pledge to my teachers the respect and gratitude that is their due;

To seek and ask the help of all my colleagues, when in interest of my patients and never refuse myself 23 such advice and help;

To refuse of any call for use of lethal venom;

I swear by Appolo the Healer, by Hygea and Panacea and by all the gods and goddesses, calling them 
Table 4 Ranking of the selected as most decisive clauses of the Version-2 (by students choosing Version-2)

Clauses

n (\%)

I will not permit considerations of age, disease or disability, creed, ethnic origin, gender, nationality, political affiliation, race, sexual orientation, social standing or any other factor to intervene between my duty and my patient;

The health and well-being of my patient will be my first consideration;

I will maintain the utmost respect for human life;

I will practise my profession with conscience and dignity and in accordance with good medical practice;

I will respect the autonomy and dignity of my patient;

I will respect the secrets that are confided in me, even after the patient has died;

I will not use my medical knowledge to violate human rights and civil liberties, even under threat;

I solemnly pledge to dedicate my life to the service of humanity;

I will share my medical knowledge for the benefit of the patient and the advancement of healthcare;

I will give to my teachers, colleagues, and students the respect and gratitude that is their due;

I will attend to my own health, well-being, and abilities in order to provide care of the highest

As a member of the medical profession: I solemnly pledge;

I will foster the honour and noble traditions of the medical profession;

\section{Supplementary Files}

This is a list of supplementary files associated with this preprint. Click to download.

- additionalfile1.pdf 